\title{
Movements and flight morphology in the endangered Large Blue butterflies
}

\section{Communication}

Piotr Skórka ${ }^{1, \star}$, Piotr Nowicki², Joanna Kudłek², Aleksandra Pępkowska², Ewa B. Śliwińska ${ }^{3}$ Magdalena Witek ${ }^{4}$, Josef Settele ${ }^{5}$, Michal Woyciechowski

IInstitute of Zoology, Poznan University of Life Sciences, 60-625 Poznan, Poland

2Institute of Environmental Sciences, Jagiellonian University, 30-387 Kraków, Poland

IInstitute of Nature Conservation, Polish Academy of Sciences, 31-120 Kraków, Poland

${ }^{4}$ Museum and Institute of Zoology, Polish Academy of Sciences, 00-679 Warsaw, Poland

${ }^{5}$ Department of Community Ecology, Helmholtz Centre for Environmental Research- UFZ, D-06120 Halle, Germany

Received 22 January 2013; Accepted 29 March 2013

Abstract: Movements and flight morphology of the endangered Large Blue butterflies Phengaris teleius and $P$. nausithous in southern Poland were studied with mark-release-recapture surveys and GIS analyses. Most individuals moved relatively small distances ( $<40$ metres) within their habitat patches. Distances covered by both species were positively related to season progression and wing length, and negatively related to body mass. P. teleius movement distances slightly exceeded those of $P$. nausithous. In addition, females moved longer distances than males, although the difference was significant only in $P$. teleius. Morphological traits appeared to be good indicators of the inter-specific and inter-sexual differences in mobility. While $P$. teleius individuals were heavier than $P$. nausithous ones, they had considerably longer wings, which may explain longer movements in the former species. Similarly, females were heavier than males in both species, but they invested more in wing size, which is likely to compensate for the negative impact of body mass on movement distances. Our results indicate that combination of GIS analysis of movement distances recorded with mark-release-recapture methods and morphometric measurements taken in field during non-lethal handling of captured individuals proved useful for studying the mobility potential of the endangered insect species.

Keywords: Dispersal • Maculinea • Metapopulation • Mobility • Morphometric measurements

(C) Versita Sp. z 0.0 .

\section{Introduction}

In light of global biodiversity loss, understanding factors affecting animal mobility has grown in importance, due to many species living in increasingly fragmented landscapes [1-3]. Higher mobility increases the probability of colonisation of vacant habitat patches as well as the chances of rescue effects for declining local populations, and thus enhances viability of entire metapopulations [1]. In turn, information on within-patch movements offers insight into space and resource use by individuals living in local populations [4,5]. It is also believed that within-patch mobility may be useful for assessing potential for inter-patch dispersal $[4,6]$.

In recent years, growing attention has been given to heterogeneity in mobility among individuals and how it is affected by morphological traits. Studies on butterflies indicate that variation in individual mobility, reflected by flight speed and acceleration capacity, can be related to differences in certain morphological parameters, particularly body mass and wing loading $[7,8]$. Furthermore, it has been found that individuals from populations that were newly established through colonisation events are larger and have relatively 
longer wings than those from more resident populations [9-11]. Similarly, butterflies living in highly fragmented landscapes - where the probability of reaching other habitat patches is low - are characterised by shorter wings and lower dispersal potential than those living in more continuous landscapes [12]. Increasing habitat fragmentation may also bring changes in relative investment in various body parts [13]. However, almost all the aforementioned and related studies assessed dispersal potential indirectly (e.g. through flight speed or acceleration capacity). What is lacking is knowledge of relationships between morphological traits and real distances covered by individuals [8].

Profound knowledge of individual mobility is especially valuable in the case of endangered species occurring in highly fragmented landscapes. In Europe, insects inhabiting semi-natural grasslands are among the most endangered animals [14,15]. Butterflies of the genus Phengaris (= Maculinea) are regarded as sensitive indicators of grassland biodiversity and as umbrella species, the conservation of which is likely to enhance numerous other co-occurring species in their habitats $[16,17]$. They have a highly specialised myrmecophilous lifestyle and depend on two crucial resources: specific foodplants and Myrmica host ants, the colonies of which are parasitised by Phengaris larvae $[16,18]$.

In the present study we examined within-patch movements of two Large Blue butterflies: $P$. teleius (Bergsträsser, 1779) and $P$. nausithous (Bergsträsser, 1779), in relation to their morphological traits. In particular, we were interested in (1) determining withinpatch movement distances covered by both species occurring sympatrically in the same habitats, (2) assessing inter-sexual differences in their movements, and (3) evaluating if morphological traits may explain variation in movement distances among individuals.

\section{Experimental Procedures}

\subsection{Field sampling}

The study was carried out in a wet meadow complex in Kraków, southern Poland, where large metapopulations of $P$. teleius and $P$. nausithous occupy patches of their Sanguisorba officinalis foodplant [19]. Three foodplant patches were chosen for intensive mark-releaserecapture surveys conducted throughout the adult flight period from early July till mid August of 2002-2004 [20]. Patch K17 was the largest (8.77 ha; maximal dimension: $500 \mathrm{~m}$ ) and surrounded by built-up areas, high reeds and forest fragments. The two smaller patches (K18: $1.06 \mathrm{ha}$; max. dimension: $180 \mathrm{~m}$; K9: $0.65 \mathrm{ha}$; max. dimension $90 \mathrm{~m}$ ) were located close to each other and were surrounded mostly by meadows without $S$. officinalis and high reeds. A more detailed description of the study sites can be found elsewhere [20,21]. Patch K9 was investigated only in 2003. Captured butterflies were marked with individual numbers written on their hind wings and immediately released. The geographic position of each capture was recorded with Garmin 12 XL GPS units, allowing ca. $3 \mathrm{~m}$ precision. Distances covered by the butterflies were calculated as straight lines between consecutive capture points. Only the distance between the first and the second capture was analyzed to avoid pseudoreplication.

The wing length, body mass and thorax width of recaptured individuals were measured directly in the field. Wing length was defined as the longest dimension of the forewing, i.e. from its basis to the tip, and it was measured to the nearest $0.5 \mathrm{~mm}$ with specially adapted millimeter paper scales. Thorax width was measured using a Mitutoyo 7313 pressure-sensitive thickness gauge with $0.01 \mathrm{~mm}$ precision. Following these measurements, the butterflies were placed in small bags and weighed with an Acculab PP2060D balance to the nearest $1 \mathrm{mg}$. However, it should be mentioned that sample size marginally differed among the three traits as several butterflies escaped while measurements were taken and, additionally, we sometimes had to abandon recording thorax width in order to maintain a constant capture effort during periods of high butterfly abundance.

\subsection{Statistical analysis}

A general linear mixed model (GLMM) was used to test the effects of species and sex on butterfly movement distances. The season progression (expressed as the number of days from July $1^{\text {st }}$ ) and time between captures were included in the model as continuous covariates. In the first step, the model was built with all the main effects and interaction terms, including year and patch ID as random factors. Patch ID had to be nested in year as patch $\mathrm{K} 9$ as surveyed only in 2003. In the final model all the main effects and significant interactions were retained. The distributions of movement distances were highly positively skewed and In-transformation was applied to achieve their normality $[22,23]$.

GLMMs were also applied to test the effects of butterfly morphology on distances covered by individual butterflies. The models were built separately for each trait: body mass, wing length and thorax width. In each case they included the effects of species, sex, season progression, time between captures and interaction terms; nonsignificant interactions were again removed from final models. In the models for wing length and thorax width, body 
mass was used as a covariate to control for its effect. As previously, year and patch ID nested within year were assigned as random factors.

Finally, in order to evaluate inter-specific and inter-sexual differences in relative investment in the investigated morphological traits, we built three further GLMMs with body mass, wing length, and thorax width as dependent variables. The two latter models, apart from the effects of species and sex as well as their interaction, also included body mass as a covariate to account for possible allometries. All the statistical analyses were performed using JMP 8 software (SAS 2006).

\section{Results}

The distances covered by both species were short relative to patch dimensions. The majority of movements were below $40 \mathrm{~m}$, and the maximum movement distances - recorded at patch $\mathrm{K} 17$ - were $423 \mathrm{~m}$ for $P$. teleius and $515 \mathrm{~m}$ for $P$. nausithous. There was a clear effect of species, with longer distances being covered by $P$. teleius individuals (Table 1). Apart from this, movement distances increased significantly with season progression, although the increase was rather gradual (slope \pm SE: $0.011 \pm 0.003$ ). The main effects were modified by the significant interaction between species and gender (Table 1). Females of $P$. teleius moved longer distances than males, while for $P$. nausithous the inter-sexual difference was not significant (Figure 1).

The investigated morphological traits were positively correlated with one another (Table 2), but body mass and wing length had opposite effects on distances covered by butterflies. The GLMMs applied for testing the effects of morphological traits (Table 3) explained $20 \%$ and $15 \%$ of the variance in individual movement distances in the case of body mass and wing length respectively, but only $5 \%$ in the case of thorax width. After controlling for

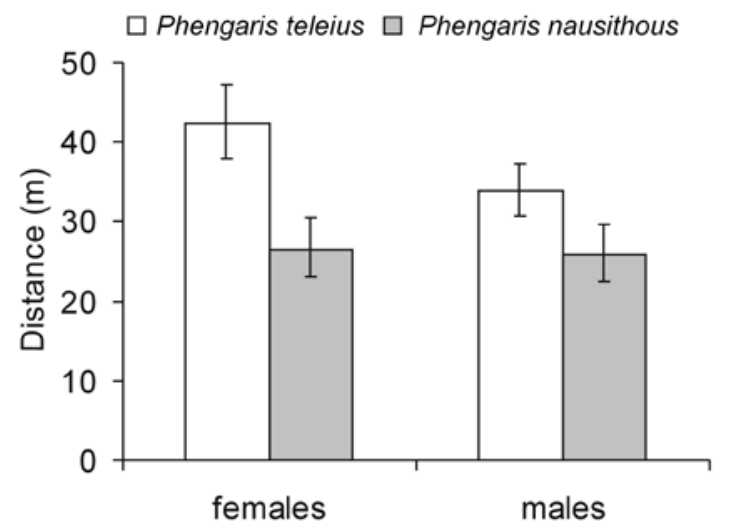

Figure 1. Within-patch movement distances (mean values with 95\% confidence intervals) of Phengaris teleius and P. nausithous.

\begin{tabular}{l|ccc}
\hline \multicolumn{1}{c|}{ Effect } & $d f$ & $F$ & $P$ \\
\hline \hline Species & $1,928.5$ & 9.712 & 0.002 \\
Sex & 1,1316 & 1.831 & 0.176 \\
Season progression & 1,1207 & 10.449 & 0.001 \\
Time span between captures & 1,1221 & 3.519 & 0.061 \\
Interaction: species*sex & 1,1192 & 4.228 & 0.041 \\
Random effects & estimate (SE) & $z$ & $P$ \\
Year & $0.003(0.023)$ & 0.13 & 0.897 \\
Site(year) & $0.034(0.008)$ & 4.25 & $<0.001$ \\
\hline
\end{tabular}

Table 1. Results of the general linear mixed model (GLMM) analysis of factors affecting within-patch movement distances covered by Phengaris teleius ( $n=373$ females and $n=457$ males) and $P$. nausithous ( $n=230$ females and $n=265$ males), (total $n=1325$ butterflies).

\begin{tabular}{l|ccc}
\hline Trait & Body mass & Wing length & Thorax width \\
\hline \hline Body mass & --- & $0.432^{* * *}(312)$ & $0.187^{*}(142)$ \\
Wing length & $0.335^{* * *}(240)$ & --- & $0.455^{* * *}(146)$ \\
Thorax width & 0.131 n.s. (131) & $0.410^{* * *}(136)$ & $\cdots$ \\
\hline
\end{tabular}

Table 2. Matrix of Pearson's correlation coefficients among the investigated morphological traits of Phengaris teleius (in top-right half) and $P$. nausithous. (in bottom-left half). Sample sizes are given in parentheses. Significance levels: ${ }^{\star \star \star}-P<0.001 ;{ }^{\star}-P<0.05 ;$ n.s. - nonsignificant. 
the effects of species and sex, we found that movement distances were negatively related to body mass (slope \pm SE: $-0.006 \pm 0.002, n=552$ individuals; Table 3, Figure 2a) and positively to wing length (slope $\pm S E=0.113 \pm 0.029$, $n=552$ individuals; Table 3 , Figure $2 \mathrm{~b}$ ). In turn, thorax width had no apparent effect on the distances covered by butterflies (slope $\pm S E=0.091 \pm 0.162, n=273$ individuals; Table 3).

The results concerning inter-specific and inter-sexual differences in morphology are presented in Table 4. We found that $P$. teleius adults were significantly heavier than $P$. nausithous, and females were significantly heavier than males regardless of the species. Even with the effect of body mass accounted for, $P$. teleius had relatively longer wings and wider thoraxes than $P$. nausithous, whereas females surpassed males in wing length but not in thorax width (Figure 3).

\section{Discussion}

Our results showed relatively low within-patch movement of Phengaris butterflies, which is in fact characteristic of most Lycaenidae [7]. Most distances were only a few tens of meters and, particularly at the largest of the investigated patches, were much shorter than the patch dimensions. This supports the hypothesis that Phengaris butterflies do not move freely within their habitat patches, instead tending to establish home ranges [24,25].

The analysis also revealed that despite occurring sympatrically in the same habitats, $P$. teleius and $P$. nausithous differ in within-patch mobility, with the former species covering longer distances. This indicates that a single $P$. teleius individual utilises more space within a habitat patch than a single $P$. nausithous. Consequently, while setting conservation targets concerning the size of habitat patches, it is advisable to prioritise $P$. teleius requirements, as patches large enough for this species should also be suitable for $P$. nausithous. Stricter spatial requirements may be responsible for the rarity of $P$. teleius relative to $P$. nausithous in recent decades in many regions of Central and Western Europe [15,26,27],
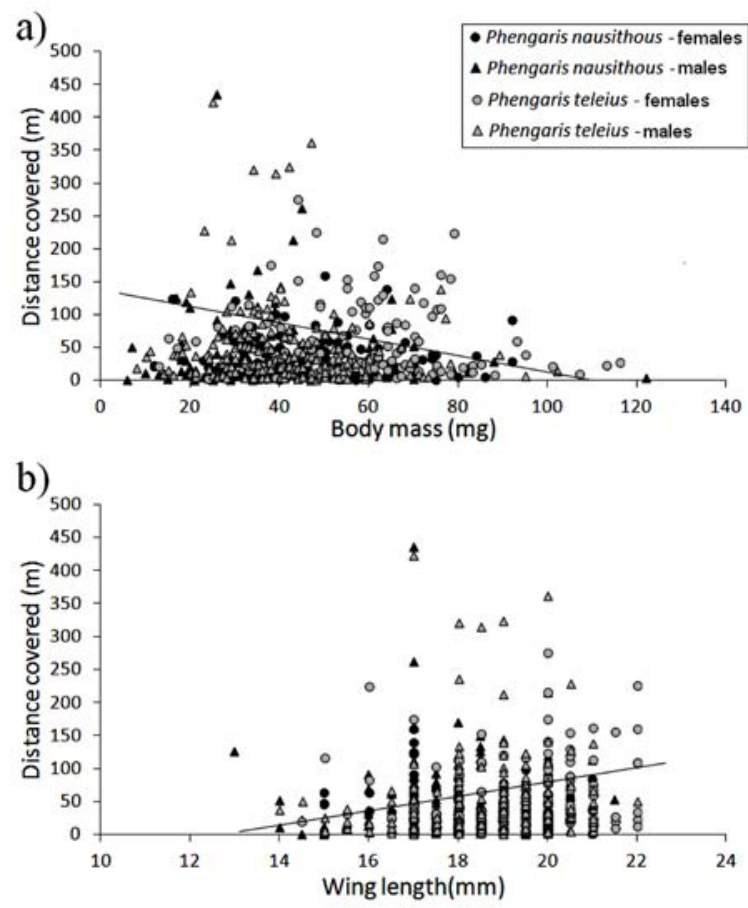

Figure 2. The effect of (a) body mass and (b) wing length on distances covered by Phengaris butterflies. The regression line is fitted to all data points (regardless of butterfly species and sex).

\begin{tabular}{l|ccccccccccc}
\hline \multirow{2}{*}{ Effect } & \multicolumn{3}{|c}{ Distances (Body weight) } & \multicolumn{3}{c}{ Distances (Wing length) } & \multicolumn{3}{c}{ Distances (Thorax width) } \\
& df & $F$ & $P$ & $d f$ & $F$ & $P$ & $d f$ & $F$ & $P$ \\
\hline \hline Body mass & 1,546 & 4.421 & 0.036 & 1,544 & 10.080 & 0.002 & 1,266 & 1.732 & 0.189 \\
Wing length & - & & & 1,544 & 12.368 & $<0.001$ & - & - & - \\
Thorax width & - & & & & - & - & - & 1,266 & 0.259 & 0.622 \\
Species & 1,543 & 16.745 & $<0.001$ & 1,520 & 9.095 & 0.004 & 1,266 & 8.437 & 0.004 \\
Sex & 1,542 & 4.222 & 0.040 & 1,542 & 2.903 & 0.089 & 1,266 & 4.336 & 0.038 \\
Season progression & 1.546 & 7.037 & 0.008 & 1,540 & 7.990 & 0.005 & 1,266 & 1.928 & 0.166 \\
Time span between captures & 1,546 & 2.636 & 0.105 & 1,544 & 2.342 & 0.127 & 1,266 & 0.154 & 0.695 \\
Random effects & estimate (SE) & $z$ & $P$ & estimate (SE) & $z$ & $P$ & estimate (SE) & $z$ & $P$ \\
Year & $0.448(0.582)$ & 0.770 & 0.441 & $0.510(269)$ & 1.288 & 0.198 & not estimated & - & - \\
Site(year) & $0.983(0.474)$ & 2.074 & 0.038 & $0.201(156)$ & 1.896 & 0.058 & not estimated & - & - \\
\hline
\end{tabular}

Table 3. The final general linear mixed models for the effects of morphological traits (in bold) on the distances covered by butterflies; the interaction between species and sex was nonsignificant in all cases. The effect of body mass was included in models for wing length and thorax width to control for allometry. Other potentially confounding factors were included in all models. 
despite much higher host ant specificity of the latter species [18].

Interestingly, a recent metapopulation-scale analysis of dispersal in Phengaris butterflies occurring sympatrically in the Czech Republic showed considerably higher emigration rate and longer interpatch movements in $P$. nausithous compared to $P$. teleius [28]. Although it is tempting to interpret the discrepancy in the findings of the above study and the present one as a manifestation of differences in mobility between the two study areas, in reality the patterns of higher within-patch mobility in $P$. teleius and higher interpatch dispersal in $P$. nausithous appear fairly consistent (see review in [29]). This suggests that there is no direct relationship between the levels of within-patch mobility and inter-patch dispersal of different species.

By contrast, the inter-sexual differences in mobility are concordant for both intra- and inter-site movements (this study; [28]). Higher mobility of females has been reported in many insects [5,30-32] and seems related to oviposition behaviour. Laying eggs in different fragments of a habitat patch or in different patches helps to maximise offspring survival, and thus female fitness, through risk spreading [2]. Distribution of butterfly males within a habitat patch is usually affected by the microdistribution and density of freshly emerged (receptive) females $[33,34]$. Since the females emerge in specific sites the distribution of males may be constrained to these sites, which may in turn result in their lower flight distances. The increase of movement distances with season progression recorded in our study may be explained in a similar way. Habitat quality is likely to deteriorate toward the end of the season-in particular, this may refer to the quality of foodplants for ovipositing females.

Two of the investigated morphological traits proved useful in understanding within-patch mobility potential. While body mass, wing length and thorax width were positively correlated with one another, they had different impacts on distances covered by butterflies. Movement distances were negatively related to body mass and positively to wing length. The same pattern has been recorded in several butterfly species $[7,11]$. In turn, even though the thorax houses flight muscles [35,36], and its mass or volume positively correlated with flight performance in other butterflies [8,35,37], it had no influence on the movement distances of Phengaris adults in our study.

Body mass and wing length appeared to be good indicators not only of individual variability, but also of
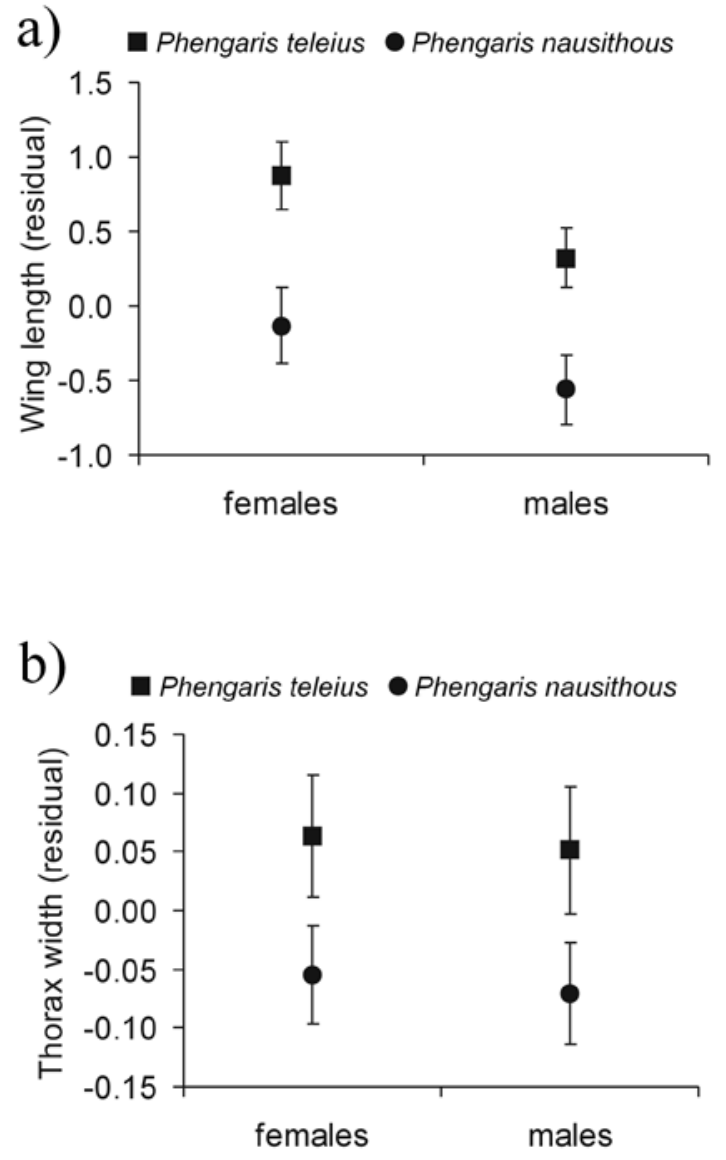

Figure 3. Inter-specific and inter-sexual differences in (a) wing length and (b) thorax width of the investigated butterflies. Values shown (means with 95\% confidence intervals) represent residuals not explained by the allometric relationship with body mass.

\begin{tabular}{c|cccccccc}
\hline \multirow{2}{*}{ Trait } & \multicolumn{2}{|c}{ P. teleius } & \multicolumn{2}{c}{ P. nausithous } & \multicolumn{2}{c}{ Inter-specific difference } & \multicolumn{2}{c}{ Inter-sexual difference } \\
& females & males & females & males & $F$ & $P$ & $F$ & $P$ \\
\hline \hline body mass $[\mathrm{mg}]$ & $56.1 \pm 1.6(133)$ & $40.7 \pm 1.2(179)$ & $50.9 \pm 1.6(109)$ & $36.9 \pm 1.4(133)$ & 9.856 & 0.002 & 104.694 & $<0.001$ \\
wing length $[\mathrm{mm}]$ & $19.5 \pm 0.13(141)$ & $18.8 \pm 0.11(192)$ & $18.4 \pm 0.12(112)$ & $17.7 \pm 0.13(138)$ & 60.290 & $<0.001$ & 4.841 & 0.028 \\
thorax width $[\mathrm{mm}]$ & $2.13 \pm 0.04(61)$ & $2.07 \pm 0.03(85)$ & $2.00 \pm 0.05(71)$ & $1.89 \pm 0.05(66)$ & 10.991 & 0.001 & 0.928 & 0.336 \\
\hline
\end{tabular}

Table 4. Morphological characteristics of Phengaris teleius and $P$. nausithous. Mean values with SE are given, together with sample sizes in parentheses. The results of the general linear mixed models (GLMMs) for the effects of species and sex are also presented; the interaction between species and sex was nonsignificant in all cases. The effect of body mass was controlled for in the models for wing length and thorax width. 
the inter-specific and inter-sexual differences in mobility. Despite $P$. teleius being heavier than $P$. nausithous the former had relatively longer wings, which may explain its longer movement distances. Similarly, females in both species were heavier than males, but they invested disproportionately more in wing size, which compensates for the negative impact of body mass on the distances covered.

Since getting direct estimates of butterfly mobility is a laborious task [38], there has been growing interest in finding morphological traits that could serve as proxies for dispersal ability $[39,40]$. The results of our study indicate that body mass and wing length are promising traits in this respect, although their predictive powers were relatively low, which is a common problem for most proxies of mobility [39]. Nevertheless, while body mass and wing length can provide only general information about butterfly movement distances, this can be enough for many purposes, e.g. for interspecific comparisons in order to set conservation priorities. Therefore, a combination of GIS-based assessment of movement distances with the analysis of morphological traits measured in the field as applied in the present study provides a useful tool for studying

\section{References}

[1] Hanski I., Metapopulation ecology, Oxford University Press, Oxford, 1999

[2] Bergman K.-O., Landin J., Distribution of occupied and vacant sites and migration of Lopinga achine (Nymphalidae: Satyrinae) in a fragmented landscape, Biol. Conserv., 2001, 102, 183-190

[3] Trakhtenbrot A., Nathan R., Perry G., Richardson D.M., The importance of long-distance dispersal in biodiversity conservation, Divers. Distrib., 2005, 11, 173-181

[4] Wiens J.A., Stenseth N.C., Van Horne B., Ims R.A., Ecological mechanisms and landscape ecology, Oikos, 1993, 66, 369-380

[5] Auckland J.N., Debinski, D.M., Clark R.W., Survival, movement, and resource use of the butterfly Parnassius clodius, Ecol. Entomol., 2004, 29, 139-149

[6] Ims R.A., Yoccoz N.G., Studying transfer processes in metapopulations: emigrations, migration and colonisation, In: Hanski I., Gilpin M.E. (Eds.) Metapopulation biology, Academic Press, San Diego, 1997

[7] Dudley R., Srygley R.B., Flight physiology of neotropical butterflies: allometry of airspeed during natural free flight, J. Experim. Biol., 1994, 191, 125-139 butterfly mobility. Incorporating body mass and wing size measurements into mark-release-recapture surveys is particularly recommendable when dealing with endangered species since these measurements can be taken without killing or prolonged handling of the study organisms [37].

\section{Acknowledgements}

We thank an anonymous referee for helpful criticism on earlier versions of this manuscript. The study was funded by the European Commission within its RTD project MacMan (EVK2-CT-2001-00126; [41]) as well as by the Polish Committee of Scientific Research within its grant SPUB-3024. PN has been supported by the by the Polish National Science Centre (grant N N304 064139). Anna Amirowicz, Malgorzata Arlet, Gabriela Krzywdzik, Dawid Moron, Balbina Kudlek, Artur Osikowski, Aleksandra Walczynska, Marta Wantuch, Jakub Woyciechowski, Kajetan Woyciechowski, Malgorzata Wojtowicz and Piotr Zygmunt helped us during the field work. We are also grateful to Tim Sparks for linguistic corrections to the manuscript.

[8] Berwaerts K., Van Dyck H., Aerts P., Does flight morphology relate to flight performance? An experimental test with the butterfly Pararge aegeria, Funct. Ecol., 2002, 16, 484-491

[9] Palmer J.O., Dingle H., Responses of selection on flight behaviour in a migratory population of milkweed bugs Oncopeltus fasciatus, Evolution, 1989, 43, 1805-1808

[10] Hill J.K., Thomas C.D., Blakeley D.S., Evolution of flight morphology in a butterfly that has recently expanded its geographical range, Oecologia, 1999, 121, 165-170

[11] Merckx T., Van Dyck H., Interrelations among habitat use, behaviour, and flight related morphology in two cooccurring Satyrine butterflies, Maniola jurtina and Pyronia tithonus, J. Insect. Behav., 2002, 15, 541-561

[12] Baguette M., Mennechez G., Petit S., Schtickzelle N., Effect of habitat fragmentation on dispersal in the butterfly Proclossiana eunomia, C.R. Biol., 2003, 326, S200-S209

[13] Norberg U., Leimar, O., Spatial and temporal variation in flight morphology in the butterfly Melitaea cinxia (Lepidoptera: Nymphalidae), Biol. J. Linn. Soc., 2002, 77, 445-453 
[14] Kuussaari M., Heliola J., Poyry J., Saarinen K., Contrasting trends of butterfly species preferring semi-natural grasslands, field margins and forest edges in northern Europe, J. Insect Conserv., 2007, 11, 351-366

[15] van Swaay C.A.M., Warren M., Red data book of European butterflies (Rhopalocera), Nature and Environment 99, Council of Europe Publishing, Strasbourg, 1999

[16] Thomas J.A., The ecology and conservation of Maculinea arion and other European species of Large blue butterfly, In: Pullin A.S. (Ed.) Ecology and conservation of butterflies, Chapman and Hall, London, 1995

[17] Settele J., Kühn E., Thomas J.A., Studies on the ecology and conservation of butterflies in Europe, Vol. 2, Species ecology along a European gradient: Maculinea butterflies as a model, Pensoft Publishers, Sofia - Moscow, 2005

[18] Witek M., Sliwinska E.B., Skórka P., Nowicki P., Wantuch M., Vrabec V., et al., Host ant specificity of large blue butterflies Phengaris (Maculinea) (Lepidoptera: Lycaenidae) inhabiting humid grasslands in East-central Europe, Eur. J. Entomol., 2008, 105, 871-887

[19] Nowicki P., Pepkowska A., Kudlek J., Skórka P., Witek M., Settele J., et al., From metapopulation theory to conservation recommendations: Lessons from spatial occurrence and abundance patterns of Maculinea butterflies, Biol. Conserv., 2007, 140, 119-129

[20] Nowicki P., Witek M., Skórka P., Settele J., Woyciechowski M., Population ecology of the endangered butterflies Maculinea teleius and $\mathrm{M}$. nausithous and the implications for conservation, Popul. Ecol., 2005, 47, 193-202

[21] Nowicki P., Halecki W., Kalarus K., All natural habitat edges matter equally for endangered Maculinea butterflies, J. Insect Conserv., 2013, 17, 139-146

[22] Underwood A.J., Experiments in ecology, Their logical design and interpretation using analysis of variance, Cambridge University Press, Cambridge, 1997

[23] Quinn G.P., Keough M.J., Experimental design and data analysis for biologists, Cambridge University Press, Cambridge,2002

[24] Hovestadt T., Nowicki P., Investigating movement within irregularly shaped patches: analysis of mark-release-recapture data using randomization procedures, Isr. J. Ecol. Evol., 2008, 54, 137-154

[25] Körösi A., Örvössy N., Batáry P., Kövér S., Peregovits L., Restricted within-habitat movement and time-constrained egg laying of female Maculinea rebeli butterflies, Oecologia, 2008, 156, 455-464

[26] Settele J., Metapopulationsanalyse auf Rasterdatenbasis, Teubner, Stuttgart - Leipzig, 1997

[27] Settele, J., How endangered is Maculinea nausithous? In: Settele J., Kühn E., Thomas J.A. (Eds.) Studies on the ecology and conservation of butterflies in Europe, Vol. 2, Species ecology along a European gradient: Maculinea butterflies as a model, Pensoft Publishers, Sofia - Moscow, 2005

[28] Nowicki P., Vrabec V., Evidence for positive densitydependent emigration in butterfly metapopulations, Oecologia, 2011, 167, 657-665

[29] Nowicki P., Settele J., Thomas J.A., Woyciechowski M., A review of population structure of Maculinea butterflies, In: Settele J., Kühn E., Thomas J.A. (Eds.) Studies on the ecology and conservation of butterflies in Europe, Vol. 2, Species ecology along an European gradient: Maculinea butterflies as a model, Pensoft Publishers, Sofia - Moscow, 2005

[30] Sculley C.E., Boggs C.L., Mating system and sexual division of foraging effort affecting puddling behaviour by butterflies, Ecol. Entomol., 1996, 21, 193-197

[31] Brommer J.E., Fred M.S., Movement of the Apollo butterfly Parnassius apollo related to host plant and nectar patches, Ecol. Entomol., 1999, 24, 125-131

[32] Bergman K.-O., Landin J., Population structure and movements of a threatened butterfly (Lopinga achine) in a fragmented landscape in Sweden, Biol. Conserv., 2002, 108, 361-369

[33] Celik T., Adult demography, spatial distribution and movements of Zerynthia polyxena (Lepidoptera: Papilionidae) in a dense network of permanent habitats, Eur. J. Entomol., 2012, 109, 217-227

[34] Takeuchi T., Mate-locating behavior of the butterfly Lethe Diana (Lepidoptera: Satyridae): do males diurnally or seasonally change their mating strategy?, Zool. Sci., 2010, 27, 821-825

[35] Thomas C.D., Hill J.K., Lewis O.-T., Evolutionary consequences of habitat fragmentation in a localized butterfly, J. Anim. Ecol., 1998, 67, 485-497

[36] Marden J.H., Variability in the size, composition and function of insect flight muscles, Annu. Rev. Physiol., 2000, 62, 157-178

[37] Turlure C., Schtickzelle N., Baguette M., Resource grain scales mobility and adult morphology in butterflies, Landscape Ecol., 2010, 25, 95-108

[38] Stevens V.M., Turlure C., Baguette M., Filling in the tapestry: a meta-analysis of dispersal in butterflies, Biol. Rev., 2010, 85, 625-642 
[39] Sekar S., A meta-analysis of the traits affecting dispersal ability in butterflies: can wingspan be used as a proxy?, J. Anim. Ecol., 2012, 81, 174-184

[40] Stevens V.M., Trochet A., Van Dyck H., Clobert J., Baguette M., How is dispersal integrated in life histories: a quantitative analysis using butterflies, Ecol. Lett., 2012, 15, 74-86
[41] Settele J., Thomas J.A., Boomsma J., Kühn E., Nash D., Anton C., et al., MACulinea butterflies of the habitats directive and European red list as indicators and tools for conservation and MANagement (MacMan), Verhandlungen der GfÖ, 2002, 32, 63 